\title{
Relationship between Student Achievement and Performance Task Scores in Math
}

\author{
Jarrent R. Tayag ${ }^{1, *}$, Marycris B. Lenon ${ }^{2}$, Joseph R. Bacanay ${ }^{2}$, Angelie M. Sotto ${ }^{2}$ \\ ${ }^{1}$ College of Education, Angeles University Foundation, Philippines \\ ${ }^{2}$ Integrated School, Angeles University Foundation, Philippines
}

Received May 17, 2020; Revised June 13, 2020; Accepted July 20, 2020

Copyright $@ 2020$ by authors, all rights reserved. Authors agree that this article remains permanently open access under the terms of the Creative Commons Attribution License 4.0 International License

\begin{abstract}
Assessment of performance tasks in the $\mathrm{K}$ to 12 curricula is vulnerable to generosity error. This implies that teachers may not be objectively assessing the performance of students thereby posing a potential disparity between the scores of the students and their actual achievement. The present study investigated the relationship between the math achievement and performance task scores of 43 4th grade pupils. The study utilized a descriptive-correlational design to examine the relationship between the results of performance tasks scores and standardized tests of the students. Results show a considerable gap between the average achievement of the pupils $(59.40 \%)$ and their performance task scores (97.57\%). Correlation results show that math achievement has a weak, but a positive relationship with the performance task scores $(r=0.311, p=0.042)$. When the performance task scores of pupils with high and low achievement scores were compared, it was found out that there is no significant difference between their scores ( $\mathrm{p}=$ 0.524). These findings imply a need to re-evaluate the assessment of learning practices particularly on performance tasks to ensure that they indeed reflect the actual achievement of students. By ensuring coherence between the two, a more accurate appraisal of the level of mastery of the students of the competencies may be acquired by teachers and school administrators.
\end{abstract}

Keywords Math Achievement, Performance Tasks, Assessment of Learning

\section{Introduction}

The mission of education has evolved from preparing learners for the world beyond school enabling them to apply the knowledge and skills learned to actual challenges they will face in a real-life setting, in present and in the future. Wiggins and McTighe [1] stress that the long-term goals of schools are making meaning of the content and transfer of learning to new situations. However, this requires a transition on the curriculum in many of the current educational reforms making performance-based assessments play a fundamental role.

In consonance with the DepEd Order No. 8 s. 2015 Policy Guidelines on Classroom Assessment for the K to 12 Basic Education Program, classroom assessment in the Philippines measures learners' achievement in relation to the content standards, performance standards and learning competencies outlined in the curriculum. To align the learning standards in assessment, grading the performance task is one of the three components.

Performance-based assessment calls for the application of knowledge and skills in the context of a real-world scenario and requires students to engage in critical thinking, analytical reasoning, and problem solving [2][3].

Advocates of performance assessments stated in several literature emphasize that performance tasks should be evaluated using well-defined performance criteria which detail on the assessment of the attributes of the processes and products performed by the students which provide the teacher with an "objective" scoring guide. This point has been reiterated by Wren [4] in his article as he presented that scoring guides or rubric are to be created to help teachers score students' responses specifically measuring the skills on critical thinking, problem solving, and written communication.

Math is a complex subject matter that teaches students problem-solving skills. The cognitive skills are deeply embedded within the discipline can be effectively assessed using both the traditional paper and pencil tests and performance-based assessment. In the former, students are typically asked to answer simple to complex mathematical calculations and problems, sometimes even extending to provide rationalization to answers. In performance-based assessments, students also do mathematical calculations 
and extend this to apply these calculations to real-life situations. To provide a comprehensive appraisal of the extent of mastery of these skills, teachers typically design both paper and pencil tests and performance-based assessments for their math students. However, while these assessments may be anchored on the same standards, it may be possible that the implementation and evaluation of the students' achievement in these two modalities differ. From a larger perspective, this may indicate a possible disparity between the actual achievement of students when gauged using these two forms of assessment. This study investigates this potential disparity between assessment results using an achievement test and performance tasks among pupils in their math class.

\section{Literature Review}

Math cognitive skills are usually taught using various topics that span from simple mechanical calculations using fundamental operations to complex problem-solving situations. As students progress through the scholastic ladder, more and more mathematical principles are introduced, which eventually translate into constants and equations. Teachers have designed an array of different strategies to deliver the content of the curriculum and ensure that students acquire the necessary competencies. However, the challenge still remains as the results of math achievement tests show unsatisfactory figures [5]. Nevertheless, the rise of a number of assessment strategies provides for opportunities to navigate the difficulties of students in the different math topics.

The traditional paper and pencil test maintain to be the persistent form of assessment for math skills even for the international assessment tests. However, several criticisms have pointed out the possible reasons for the low performance of students in these examinations. For example, the reading difficulty of students tends to hinder them from applying what they actually know [6]. Students can easily solve equations but find it difficult to comprehend a worded problem probably because of language barriers. Considering this dilemma, teachers turn to performance-based assessments to monitor the achievement of students.

Performance-based assessments explore the application of math concepts in a real-world situation. This can be used to teach students mathematical concepts or evaluate what they have learned from their lessons. While performance-based assessments are usually multifaceted, the focus is given to the assessment of the understanding of the students towards the concepts taught to them. Performance-based assessments have not only been reported better math achievement among students [7], it has also been shown that these forms of assessment develop the confidence of students in engaging in problem-solving activities [8].
Performance-based assessments, however, also have their limitations. Similar to traditional assessment, the activities should be anchored with the standards being assessed. However, unlike the traditional assessment, the implementation of performance-based assessment must also be carefully monitored to ensure that students are focused on the standards and not with other aspects of the tasks. Because of the multifaceted nature of the performance, students can wander from making the presentation more "creative" rather than accurate. This is why teachers must introduce the rubrics for evaluation prior to the implementation of the activity. The rubric is supposed to enumerate the expected outcomes of the activity, as well as the standards by which the performance will be evaluated. There must be a clear alignment between these standards and the curriculum to ensure that the assessment is valid.

Buyukkidik and Anil [9], however, found out that there is variability in the reliability of rubrics used to evaluate the performance of students in math. It has been shown in their study that students tend to have higher scores when an analytic rubric is used, compared to a holistic rubric. This raises the issues about not only the alignment between the curriculum and the rubric, but even the design and format of the rubric used.

Regardless of the form of assessment used, the goal remains to be the same, which is to appraise the level of mastery of students across the competencies set prior to the delivery of instruction. It is therefore imperative that teachers implement these assessment tools properly to obtain valid data. Duhon, House, and Stinnett [10], however, reported a possible difference in the results of different assessment monitoring procedures. In particular, the study compared the assessment results from a computer-aided tool and the traditional paper and pencil tests. This study calls for a closer examination of the designs and implementation of various assessment procedures to ensure valid results. In the context of the present study, considering that the achievement test and the performance-based assessments are anchored on the same standards, they must produce analogous data on the level of achievement of the students. Discrepancies on this may hint concerns about the design and implementation of the assessment tools used.

\section{Materials and Methods}

\subsection{Research Design}

The study employed a descriptive-correlational design, in which the target variables were analyzed for the possible association. In this design, the scores of students in the math achievement test and in their performance tasks were explored. The achievement test was administered at the end of the academic year covering the different topics 
discussed for the four quarters. The performance task is a form of performance assessment that is given as a culmination of the topics discussed for the subject. In terms of scope, the two assessment tools are expected to be the same. The most apparent difference, however, is the form in which they are administered. The achievement test takes the form of a paper and pencil examination, while the performance assessment focuses on the execution of the skills in a classroom project. Math, a subject which emphasizes cognitive skills in problem solving, is deemed to be an appropriate discipline for this study since its competencies can be effectively assessed using both forms of assessment.

\subsection{Data Sources}

\subsubsection{Achievement Test Scores}

The achievement test was administered by a commercial company at the end of the academic year. It comprises of 40 items involving various math skills that were taught for the four quarters. The test score reports were also prepared by the company and given to the school a month after the administration.

\subsubsection{Performance Task Scores}

The performance task is a culminating activity designed to gauge the students' comprehensive understanding of the different math skills covered for the four quarters. The assessment utilizes a rubric that evaluates the accuracy of computations, application of math concepts, and presentation of the students. The performance activity was done individually by the students. The activity was done for four sessions ( a week).

\subsection{Participants}

The participants were 43 fourth grade students in a private school in the Philippines. They have all been enrolled in the school since the first quarter and were able to participate in all the activities in the classroom and the school for the last four quarters.

\section{Results and Discussion}

\subsection{Achievement Test and Performance Task Scores}

The mean scores and standard deviations of learners in the achievement tests and performance assessments are provided in table 1 . The students obtained an average percentage score of 59.40 with a standard deviation of 16.30 in the achievement test. The mean score of the students in the performance assessment is 97.57 with a standard deviation of 2.2. This means that scores of the students in the achievement test are more spread around the mean; there were students who obtained extremely low and extremely high scores. In contrast, scores for the performance assessment are less spread; most of the students' scores are centered around the mean.

The results are consistent with the findings of Mahendra [7], which pointed out that students tend to have higher scores on performance-based assessments. However, the data from the table bring about some questions on the validity of the tools used. If decisions are to be based solely on the achievement test, it can be surmised that the students have barely reached a target $75 \%$ mark. This is directly contradicted by the performance-based assessment results, which indicate a very high level of mastery of the skills.

Table 1. Mean scores of learners in achievement test and performance assessment

\begin{tabular}{|c|c|c|}
\hline Assessment tool & Mean Percentage & $\begin{array}{c}\text { Standard } \\
\text { Deviation }\end{array}$ \\
\hline Achievement test & 59.40 & 16.30 \\
\hline Performance assessment & 97.57 & 2.2 \\
\hline
\end{tabular}

\subsection{Correlating Achievement Test and Performance Task Scores}

A significant correlation was found between achievement test scores and performance assessment scores $(\mathrm{p}<0.05)$ as seen in table 2. Correlation results $(\mathrm{r}=$ $0.311, \mathrm{p}=0.042$ ) show that math achievement has a weak, but a positive relationship with the performance assessment scores. This indicates that students with high achievement test scores tend to have high performance assessment scores. While there is an apparent gap between the mean scores of the two assessment tools, it can be surmised from the findings that score trends are associated with each other.

Table 2. Correlation between achievement test scores and performance assessment scores

\begin{tabular}{|c|c|}
\hline Pearson Correlation & p value \\
\hline 0.311 & $0.042^{*}$ \\
\hline
\end{tabular}

To further explore the data, the students were divided into two groups based on their scores on the achievement test. The achievement is used as a basis because it has undergone standardization. The students were arranged according to their scores and divided equally into upper and lower scoring groups. The scores of these groups in the performance task were compared to see if the activity can actually distinguish between the upper and lower scoring groups.

In contrary to the result in table 2, the result on table 3 shows no significant difference between performance task scores of pupils with high achievement scores and performance task scores of pupils with low achievement scores $(\mathrm{p}>0.05)$. This means that scores in the performance task may be high regardless of the students' math achievement. These results imply a need to re-evaluate the assessment of learning practices 
particularly on performance tasks to ensure that they indeed reflect the actual achievement of students. This result validates the study of van Ewijk [11] that teachers' grading practices consider other factors rather than just the abilities of the students. The difference in the administration and grading of performance tasks and written tests in math may explain the disparity in the results. Unlike in written tests wherein teachers can easily evaluate a student answer as either right or wrong, performance assessments lend a margin of consideration for the teacher in evaluating student outputs. While rubrics are used in the assessment, it is possible that teachers offer more accommodation for students in terms of evaluating their effort rather than their actual output.

Table 3. Comparison of performance task scores of learners with high and low achievement scores

\begin{tabular}{|c|c|c|}
\hline $\mathbf{t}$ & df & p value \\
\hline 0.642 & 41 & 0.524 \\
\hline
\end{tabular}

\subsection{Discussion}

Assessment is an essential component of teaching and learning [12]. Through assessment, teachers can monitor the progress of students in the curriculum. Valid assessment data can help tools in formulating relevant programs and policies to support student development in the school [13][14]. Communicating accurate assessment results to various stakeholders such as school heads and parents can enable them to participate more actively in the decision-making processes concerning students' education. These, among others, are pivotal considerations in designing, implementing, and evaluating assessment activities for students.

The prevalence of paper and pencil tests both in the classroom and international assessment initiatives has been criticized for its inability to capture the totality of students' knowledge and skills. Math, in particular, has been the center of many of these examinations. Recent curricular reforms pushed forward the use of alternative assessments for math [15]. While paper and pencil tests have been redesigned to ensure that they can capture different levels of cognition and understanding, performance-based assessments are seen to provide a wider array of skills for assessment.

The results of the present study point out to a possible disparity between the assessment conducted in the paper and pencil achievement test and performance-based assessment. While the association between the scores highlights a similarity in the trend, the gap between the mean scores of the two tools hints potential issues on the design and implementation of the tasks. This paper looked at the influence of generous effect from the teachers who evaluated the output of the students in the performance task. While discussing these explanations, several assumptions are made. First, the achievement test, being standardized, is considered as the benchmark for comparison. Second, the two tools are anchored on the same standards. Efforts have been made to ensure this, including the appraisal of the table of specifications of the achievement test and comparing it with the rubrics for evaluation of the performance task. The standards in the rubric are found to be aligned with the curriculum. Thus, from these, it can be surmised that the design of the activity in itself is valid, at least from the perspective of curriculum alignment.

Eliminating the potential flaws in the design, the evaluation phase using the rubric is deemed to be the most plausible source of the disparity. Unlike in a standardized achievement test where the answers are quite objective, the evaluation of performance by the teacher may have room for subjectivity. Indeed, standards are set and that all possible outputs were considered; however, teachers tend to be more lenient in evaluating performance-based assessments. Such leniency is based on the idea that these forms of assessments are supposed to help the students pull up their point average for the subject, rather than reflect their actual performance. It is apparent in the achievement test results that the students may have difficulties in their traditional assessments. Thus, to ensure that students are able to pass the course, they need an activity that could help them catch up. Teachers often look at performance assessments to help the students in this area.

Because of such generosity, teachers tend to give higher marks for students than they actually deserve. In other cases, teachers would design simpler performance tasks to ensure that students can accomplish them. When the levels of complexities are compared, it is apparent that paper and pencil tests are more challenging for students. These issues pose significant problems in interpreting the results of the assessment. Because of the influence of generous effect in the assessment results, it is almost impossible to discriminate the students who have mastered the competencies from those who have not by using the data from the performance activities. From a bigger perspective, this creates a problem on policy formulation and school program design as stakeholders are given the illusion that students are performing better than they actually do.

Performance-based assessments are promising tools for evaluation. However, they can only be useful if they are able to produce valid results. Teachers and students must be able to benefit from these forms of assessment according to their function so as to properly assist the latter in realizing their level of achievement and be able to participate in activities that could further hone their skills.

\section{Conclusions}

The study investigated the relationship between student achievement and performance task scores in math. The findings of the study show that there is a significant correlation between the math achievement scores and the 
performance task scores. However, no significant difference is found between the performance task scores of pupils with high achievement scores and low achievement scores. The study findings suggest that (a) the design of the performance task should require the students to demonstrate the skills aligned to the curriculum standards and with sufficient depth and breadth to reflect the actual achievement of the students (b) performance tasks should have a well-defined scoring system that allows the teacher to evaluate a performance or product according to the actual standards in the curriculum.

\section{REFERENCES}

[1] Wiggins, G., \& McTighe, J. (2008). Put understanding first. Educational Leadership, 65(8), 36.

[2] Baker, E. L., O'Neil, H. F., \& Linn, R. L. (1993). Policy and validity prospects for performance-based assessment. American psychologist, 48(12), 1210.

[3] Chun, M. (2010, March). "Taking teaching to (performance) task: Linking pedagogical and assessment practices." Change: The Magazine of Higher Education.

[4] Wren, Douglas (2015). Assessing $21^{\text {st }}$-Century Skills with Performance Tasks: The Five-Year Journey of a Large School Division. Virginia Educational Leadership, 12.

[5] Dancis, J. (2014). What Does the International PISA Math Test Really Tell Us?. AASA Journal of Scholarship and Practice, 10(4), 31-42.

[6] Lamb, J. H. (2010). Reading grade levels and mathematics assessment: An analysis of Texas mathematics assessment items and their reading difficulty. The Mathematics Educator, 20(1).
[7] Mahendra, I. (2016). Contextual learning approach and performance assessment in mathematics learning. International Research Journal of Management, IT \& Social Sciences, 3(3), 7-15.

[8] Arhin, A. K. (2015). The Effect of Performance Assessment-Driven Instruction on the Attitude and Achievement of Senior High School Students in Mathematics in Cape Coast Metropolis, Ghana. Journal of Education and Practice, 6(2), 109-116.

[9] Büyükkidik, S., \& Anil, D. (2015). Investigation of reliability in generalizability theory with different designs on performance-based assessment. Egitim ve Bilim, 40(177)

[10] Duhon, G. J., House, S. H., \& Stinnett, T. A. (2012), Evaluating the generalization of math fact fluency gains across paper and computer performance modalities. Journal of school psychology, 50(3), 335-345.

[11] Van Ewijk, R. (2011). Same work, lower grade? Student ethnicity and teachers' subjective assessments. Economics of Education Review, 30(5), 1045-1058.

[12] Breda, A., Pino-Fan, L. R., \& Font, V. (2017). Meta didactic-mathematical knowledge of teachers: criteria for the reflection and assessment on teaching practice. EURASIA Journal of Mathematics, Science and Technology Education, 13(6), 1893-1918.

[13] Zullig, K. J., Koopman, T. M., Patton, J. M., \& Ubbes, V. A. (2010). School climate: Historical review, instrument development, and school assessment. Journal of psychoeducational assessment, 28(2), 139-152.

[14] Yemini, M. (2012). Internationalization assessment in schools: Theoretical contributions and practical implications. Journal of Research in International Education, 11(2), 152-164.

[15] Oberg, C. (2010). Guiding Classroom Instruction through Performance Assessment. Journal of Case Studies in Accreditation and Assessment, 1, 1-11. 